УДК 786.2;781.68
DOI https://doi.org/10.31723/2524-0447-2020-30-2-13

Ольга Валерьевна Чеботаренко

ORCID: 0000-0001-8537-9264

кандидат искусствоведения,

доцент кафедры музыковедения, инструментальной

и хореографической подготовки

Криворожского государственного педагогического университета hvostic7@gmail.com

\title{
КОНФЛИКТ КАК ЭСТЕТИЧЕСКИЙ ПРИНЦИП И ПСИХОЛОГИЧЕСКИЙ ФЕНОМЕН В ПРОЦЕССЕ МУЗЫКАЛЬНОГО ТВОРЧЕСТВА
}

Цель работы - выявить особенности и основные составляющие конфликта, понимаемого как эстетический принцип и психологический феномен, на основе которых рождается то особое психологическое напряжение, которое отличает игру выдающихся музыкантов-исполнителей. Методология исследования обусловлена использованием феноменологического и психологического методов для выявления спещифики конфликта в процессе музыкального интонирования, метода системного и структурного анализа для выявления многоплановой структуры художественных явлений, составляющих основу напряжения в музыкальном исполнительстве, и метода обобщения в выводах. Данные методические подходы дают возможность подойти к конфликту как $\kappa$ основе процесса музыкального исполнения, эстетическому принципу и психологическому феномену. Научная новизна заключается в расширении подходов к изучению конфликта как эстетического приниипа и психологического феномена в процессе музыкального творчества; в углублении психологического подхода при изучении процесса музыкального исполнения; в привлечении специфики дирижерской деятельности, что является принципиально важным для концертирующего пианиста. Выводы. На основе проделанного анализа можно заключить, что конфликт как эстетический принцип и психологический феномен является важной составляющей музыкального исполнения, которое способно выявить сущность музыки как «вечно изменчивое противоречие» (А. Лосев), как конфликт разнонаправленных векторов (И. Браудо). Данное явление имеет сложную и многоплановую структуру, которая создает особое энергетическое напряжение (как в звучащем, так и в незвучащем пространстве) в музыкальном интонировании, подчиненное воле музыканта-исполнителя. Изучение природы конфликта как важной составляющей дает возможность исполнителю не только понять

(ㄷ) Чеботаренко О. В., 2020 
особенности игры выдающихся музыкантов, но и углубить свое понимание музыкального языка и секретов исполнительского мастерства.

Ключевые слова: конфликт, противонаправленные энергии, энергетический поток, ритмические аномалии, интонационное напряжение.

Chebotarenko Olha Valeriivna, Candidate of Art History, Associate Professor at the Department of Musicology, Instrumental and Choreographic Training of the Kryvyi Rih State Pedagogical University

Conflict as an aesthetic principle and a psychological phenomenon in the process of musical creative activity

Research objective. The purpose of the work is to specify the features and key components of the conflict, understood as an aesthetic principle and psychological phenomenon, as the basis for the special psychological tension to be born, that distinguishes the performance of outstanding musicians. The methodology determined by the use of phenomenological and psychological methods to identify the specifics of the conflict in the process of musical intonation, the method of systemic and structural analysis in order to identify the multifaceted structure of artistic phenomena forming the basis of tension in musical performance as well as the method of generalization in conclusions. These methodological approaches make it possible to examine the conflict as the basis of the process of musical performance, an aesthetic principle and a psychological phenomenon. The scientific novelty is presented in the expansion of approaches to the study of conflict as an aesthetic principle and psychological phenomenon in the process of musical creative activity; in deepening the psychological approach when studying the process of musical performance; in attracting the specifics of conducting, which is fundamentally important for a concert-performing pianist. Conclusions. Owing to the analysis carried out, we can conclude that conflict as an aesthetic principle and psychological phenomenon is an important component of musical performance, which can reveal the essence of music as an "ever-changing contradiction" (A. Losev), as a conflict of multidirectional vectors (I. Braudo). This phenomenon has a complex and multifaceted structure, which creates a special energetic tension (both in the sounding and non-sounding space) in musical intonation, subjected to the will of the musician-performer. The study of the conflict nature as an important component enables the performer not only to comprehend the peculiarities of the performing character of outstanding musicians, but also to deepen their own understanding of the musical language and the secrets of performing skills.

Key words: conflict, opposing energies, energy flow, rhythmic anomalies, intonation tension.

Чеботаренко Ольга Валеріївна, кандидат мистецтвознавства, доцент кафедри музикознавства, інструментальної та хореографічної підготовки Криворізького державного педагогічного університету

Конфлікт як естетичний принцип та психологічний феномен у процесі музичної творчості

Мета роботи - виявити особливості й основні складові частини конфлікту, який розуміється як естетичний принцип та психологіч- 
ний феномен, на основі яких народжується те особливе психологічне напруження, що вирізняє гру видатних музикантів-виконавців. Методологія дослідження зумовлена використанням феноменологічного та психологічного методів для виявлення специфіки конфлікту у процесі музичного інтонування, методу системного та структурного аналізу для з'ясування багатопланової структури художніх явищ, що становлять основу напруження в музичному виконавстві, та методу узагальнення у висновках. Дані методичні підходи дають можливість підійти до конфлікту як до основи процесу музичного виконання, естетичного принципу та психологічного феномену. Наукова новизна полягає в розширенні підходів до вивчення конфлікту як естетичного принципу та психологічного феномену у процесі музичної творчості; у поглибленні психологічного підходу під час вивчення процесу музичного виконання; у залученні специфіки диригентської діяльності, що є принципово важливим для піаніста, який концертує. Висновки. На основі зробленого аналізу можсна зазначити, що конфлікт як естетичний принцип та психологічний феномен є важливою складовою частиною музичного виконання, що здатний виявити сутність музики як «вічно мінливої суперечності» (О. Лосєв), як конфлікту різноспрямованих векторів (I. Браудо). Це явище має складну та багатопланову структуру, що створює особливе енергетичне напруження (як у просторі, що «звучить», так $i$ в тому, що «не звучить») у музичному інтонуванні, що підпорядковане волі музиканта-виконавия. Вивчення природи конфлікту як важливої складової частини дає можллвість виконавцю не тільки розуміти особливості гри видатних музикантів-виконавців, але й поглибити своє розуміння музичної мови та секретів виконавської майстерності.

Ключові слова: конфлікт, протилежно спрямовані енергіі, енергетичний потік, ритмічні аномалї̈, інтонаційне напруження.

Актуальность темы исследования. Понятие конфликта сегодня применяется очень широко в различных областях научного гуманитарного знания (А. Анцупов, А. Шипилов). Как отмечает Н. Гришина, несмотря на активное изучение, проблемы, возникающие в связи с определением конфликта, и сегодня еще далеки от разрешения [3, с. 18].

Конфликт как постоянная внутренняя жизнь индивида рассматривался 3. Фрейдом, К. Хорни, Э. Эриксоном, К. Юнгом и другими; в социальном контексте исследован А. Адлером; конфликт музыки в контексте нравственности в культуре постмодернизма рассматривался Н. Адаевой. По мнению Н. Гришиной, в классической психологии конфликт понимается: «1) как явление, природа которого определяется через интрапсихологические процессы и факторы; 2) как явление, возникновение и особенности которого определя- 
ются, прежде всего, ситуацией; 3) как явление, для понимания которого недостаточно знания личностных особенностей или объективного описания ситуации, но необходимо понимание когнитивной составляющей - субъективной интерпретации происходящего» [3, с. 77-78].

Исполнительское искусство сегодня занимает не только важное место в культуре, оно достигло очень высокой степени технологического развития и художественного мастерства. Хотя, конечно, мы не можем говорить о расцвете или эволюции сугубо технического уровня, так как предыдущие эпохи прославились феноменами виртуозов в высшей степени этого слова (Ф. Лист, Ф. Бузони, С. Рахманинов, В. Горовиц и другие). Однако все чаще известные музыканты-исполнители отмечают, несмотря на то, что многих пианистов отличает безукоризненная техника, все меньше становится выдающихся личностей (интервью Э. Вирсаладзе, Г. Кремер и других).

Всегда существовали исполнители различных уровней одаренности, искусство которых воспринимала и понимала публика либо элитарная, либо ждущая особых виртуозных внешних эффектов, или молодежь, ожидающая, что с ней будут говорить на одном языке - понятном, доступном и близком (например, популярные концерты классической музыки на открытых парковых пространствах, с небольшой сценой рядом с расположившейся на траве публикой концерт Д. Трифонова, где звучит Ф. Шопен, фантазия-экспромт). Однако нас интересует вопрос, что же отличает игру выдающихся исполнителей, которая производила и производит огромное впечатление, оставляет глубокий след в сознании.

Среди важных составляющих музыкального исполнения отметим особое напряжение, которое создается в процессе исполнения и имеет огромное воздействие на слушателя. Как отмечает Э. Хага, интенсивность и напряженность тона является отличительной чертой музыкального воздействия исполнителя [7, с. 83]. Можно предположить, что данное напряжение рождается вследствие конфликта, который возникает на различных уровнях, количество которых довольно велико (не ограничивается психическим, физиологическим, эстетическим, художественным, социальным и другими). Однако нас будут интересовать первые четыре уровня. 
Цель исследования - выявить особенности и основные составляющие конфликта, понимаемого как эстетический принцип и психологический феномен, на основе которых рождается то особое энергетическое напряжение, которое отличает игру выдающихся музыкантов-исполнителей.

Научная новизна статьи состоит в расширении подходов $\mathrm{K}$ изучению конфликта как эстетического принципа и психологического феномена в процессе музыкального творчества; в углублении психологического подхода при изучении процесса музыкального исполнения; в привлечении специфики дирижерской деятельности, что является принципиально важным для концертирующего пианиста.

Изложение основного материала. А. Лосев отмечал особую «слитость» между противоположными сущностями. Данные «сущности», которые изображаются в музыке, на взгляд ученого, «слиты до полной нераздельности и нерасчленимости, хотя присутствуют в музыке всею своею существенностью» [4, с. 232]. Особое напряжение, состояние конфликтности создается благодаря сочетанию множества противонаправленных энергий. «Чистое музыкальное бытие все пронизано бесконечными энергиями и силами, оно есть нечто постоянно набухающее и трепещущее, живое и нервное. В музыкальном произведении каждый его момент пронизан бесчисленным количеством сил; он - своеобразное средоточие и фокус жизненных токов цельного организма <...> Музыка - бесформенное единство самопротивоборствующих моментов взаимопроникновенного множества» [4, с. 240]. Данная мысль А. Лосева очень ярко выявляет сущность специфического психологического напряжения, которое пронизывает исполнительский процесс и особо раскрывается в третьем основоположении А. Лосева: «Чистое музыкальное бытие есть всеобще-нераздельное и слитно-взаимопроникновенное самопротивоборство» (курсив наш - О. Ч.) [4, с. 241].

Поток энергий управляется волей музыканта, от силы которой зависит и сила воздействия исполнения. Как отмечает ученый, «воля - становящаяся предметность; предметы этапы волевого и вообще переживательного самопорождения. Борьба бытия с самим собой и - бессубъектное самочуствие безобъектных обстояний» [4, с. 245]. Особую важность для нашего исследования приобретает пятое основоположение А. Лосева, которое говорит о том, что «субъект музыкального 
суждения есть вечно изменчивое самопротиворечие, данное как жизнь (или данное как чистое самопротиворечие неоднородно текущего времени)» [4, с. 248]. Данное «самопротиворечие» можно рассматривать как психологический конфликт, содержащийся в музыке и воплощающийся в исполнении, что рождает особый исполнительский феномен.

Важными являются высказывания И. Браудо о двух видах энергии, которые пронизывают исполнение музыки И. Баха. Выявляя их различие, исследователь отмечал, что первое - это энергия воли; второе - результат свойств материала [2, с. 18]. Исследователь описывает различные элементы «самопротиворечия» в музыке, например, в природе скачка он отмечает силу, а в секунде - инерцию, отмечая, что сила и инерция слиты в процессе движения. «Инерция есть свойство материи. Но, с другой стороны, она - эхо силы: эхо, звучащее лишь благодаря свойствам материи и все же повторяющее осмысленное восклицание силы. Сила - активна, тело - пассивно. В явлении инерции происходит как бы слияние движущего и движущегося. Инерция не есть только «инертность», но и энергия» [2, с. 19]. Данная цитата нам очень важна, так как помогает выявить природу психологического и физиологического конфликта, который в процессе исполнения превращается в художественный.

И. Браудо очень тонко отмечает, что в процессе исполнения бывают парадоксальные вещи, когда максимальное напряжение достигается в моменты «незвучания»: «явления артикуляции (звукового осуществления) отнюдь не параллельны явлениям мелодической пластики. Возможны случаи, когда именно цезуре, нулевой звуковой точке, соответствует максимальное динамическое напряжение, и наоборот прочнейшей звуковой спаянности, моментам напряженного звукового осуществления соответствуют пластические образы инерции)» [2, с. 19]. Эти парадоксальные явления во многом отличают игру больших исполнителей, когда происходит удивительная недосказанность и напряженность звенящей тишины (можно вспомнить совет Г. Нейгауза С. Рихтеру выдерживать перед началом игры сонаты си минор Ф. Листа длительную паузу для создания необходимого психологического напряжения и волнения публики).

Конфликт противоположных художественных интенций определяет энергетическое движение, с присущим ему 
напряжением потока. Процесс музыкального интонирования движим данным конфликтом, с его эффектом борьбы с материалом, что приводит к впечатлению упругости натянутой непрерывной струны, насыщает интонацию особой выразительностью. «Упругость этой струны концентрирует свое давление на гранях нашей звуковой системы, на ступенях. Ступени являются нам как точки приложения напряжения сплошного звукового поля» [2, с. 19].

Исследование процесса интонирования привело И. Браудо также к необходимости рассмотрения понятия воли, следовательно, и толкования феномена мелодии как психического явления. Ученый определил очень важные позиции, относящиеся к специфике музыкального исполнительского процесса (как временного, так и интонационного и пространственного). И здесь тоже можно выявить конфликтные ситуации или наличие противонаправленных векторов. Изучая зигзагообразность баховской темы, И. Браудо отмечал, что сопротивление вызывает силу, а действие силы узнается лишь по борьбе с тяжестью, что проявляется именно в изгибах. При исполнении барочной музыки особую сложность представляет ощущение подобного напряжения, которое рождается при интонировании интервалов, мелодических изгибов, опеваний и так далее. Как отмечал исследователь, «изогнутая пластина прочней прямой. Причина этого в том, что сложнее и многообразнее связи, которые нужно разрывать, сгибая пластину. То же и в мелодической линии. Тем сильнее утверждает она свою форму, чем больше вмещает в себе разнородных пластических натяжений. Натяжения побочных деталей укрепляют основное направление» [2, с. 21].

Таким образом, процесс интонирования мелодической линии (да и не только) может быть представлен как особая сила, которая рождается в процессе борьбы с тяжестью (в изгибах мелодии), при наличии разнообразных пластических натяжений, понижении и повышении (также сюда можно отнести и физическое сопротивление клавиши при нажатии, и временной конфликт ритмических фигур с метром, ощущение сильной доли - особенно при синкопах, полиритмии и так далее). «Каким образом развернуть длительный процесс в узком звуковом поле? Очевидно, что здесь на помощь приходит изгиб. Изгиб концентрирует энергию, собирая большое напряжение на небольшом (вертикально) пространстве» [2, с. 21-22]. 
Важное место проблемы исполнительского времени занимают в работах М. Аркадьева. Говоря о специфике дирижерского жеста, исследователь рассматривает его двойственную природу, в которой обнаруживается определенная конфликтность, и отмечает, что музыка и оркестр обладают различной природой. «Дирижирование музыкой» и «дирижирование оркестром» представляют некоторое противоречие. «Чем выразительнее жест, чем более он стремится передать стихию музыки, тем менее ясным становится видимая структура жеста («феномен Фуртвенглера»), и наоборот. Задача мастера - соединить эти две постоянно борющиеся тенденции» [1].

Особую сложность для исполнителя представляют «ритмические аномалии», которыми изобилует музыкальный текст, начиная с XIX столетия. Анализируя музыку Л. Бетховена, Р. Шумана и других, М. Аркадьев отмечает «конфликтные» отношения между звучащими и незвучащими элементами (когда отсутствуют звучащие сильные доли в тексте). Именно отсутствие звучащих долей создает особое напряжение: «для дирижера и оркестрантов, а также для всех, знающих партитуру, эти напряженные, полные драматизма синкопы обладают ярко выраженным смыслом, они передают через особое ощущение метроритмического столкновения незвучащих, выраженных в жесте дирижера, акцентов и звуковых пластов страстную, мятежную душу Манфреда. В синкопированном виде эти аккорды требуют совершенно иной исполнительской энергии, чем, если бы они были записаны «нормально»» [1]. Исследователь приходит к очень важному выводу о том, что параллельно сосуществуют два пласта: метр - как незвучащий внутренний пульс и непрерывный внутренний поток музыкального времени-энергии (где паузы лишь «просветы» его). Характерным является то, что подобный конфликт звучащего и незвучащего, как правило, чувствуют все дирижеры, но это чувство жизненно необходимо всем остальным исполнителям. И мы присоединяемся к мнению М. Аркадьева, что «для профессионала, в целях обострения своей профессиональной интуиции и насколько возможно полного и глубокого владения музыкальной тканью, крайне важно ОСОЗНАТЬ это» [1].

Этот психологический конфликт, который организовывается на уровне мышления исполнителя, создает в звучашем музыкальном потоке напряжение сопротивляемости, осяза- 
емости и гибкости временной ткани; эти качества, в свою очередь, определяются жизнью «незвучащей» материи, незвучащего «времени-энергии», которую необходимо сотворить и как непрерывность, и как пульс. «Bсе accelerando и ritenuto осуществляются на уровне незвучащего пульса, это принципиальное требование нашему слуху, нашей креативности и «исполнительскому порыву». А все паузы получают свою реальность и семантику, всю свою тематичность как следствие внутренней жизни «незвучащего» на протяжении всего произведения. Паузы - лишь просветы «незвучащего» в ткани музыкального развертывания» [1]. Таким образом, обладание в сознании и мышлении этими двумя как бы независимыми структурными рядами (двумя пластическими и выразительными потоками - «незвучащим» и «звучащим») насыщает исполнительскую интерпретацию особой энергетической напряженностью, глубиной и магнетической силой.

Ocoбое значение, как «несущей функции» в становлении целостного музыкального материала, М. Аркадьев отводит «незвучащему пласту», который является «непрерывностью», той пульсирующей внутренней энергией («время-энергия»), которая не только не подлежит звуковому воплощению, но и в принципе не допускает его. Как отмечает Л. Мазель, исполнитель для «Полного профессионального овладения музыкальной тканью должен обладать гештальтом (образом) «незвучащего» пульсационного экспрессивного континуума. Наконец, «звучащий» и «незвучащий» пласты произведения находятся в сложном диалектическом взаимодействии, нередко конфликтном» [5].

Выводы. На основе осуществленного анализа можно заключить, что конфликт как эстетический принцип и психологический феномен является многоаспектной областью и важной составляющей музыкального исполнения, которое способно выявить сущность музыки как «вечно изменчивое противоречие» (А. Лосев), как конфликт разнонаправленных векторов (И. Браудо). Данное явление имеет сложную, во многом скрытую внутреннюю многоплановую структуру, обеспечивает особое психологическое напряжение (как в звучащем, так и в незвучащем пространстве) в музыкальном интонировании, всецело подчинено воле музыканта-исполнителя. Изучение природы конфликта как важной составляющей дает возможность исполнителю не только выявить 
особенности игры выдающихся музыкантов, но и углубить свое понимание музыкального языка и секретов исполнительского мастерства.

Именно психологическое напряжение как «направляющая активности личности, вектор активности сознания» (А. Самойленко) не только отличает одного исполнителя от другого, но и дает возможность судить о глубине понимания композиторского текста. Сегодня исполнитель стоит перед очень сложным выбором для того, чтобы найти свое место в искусстве.

Формирование музыканта-исполнителя требует не только определенного времени и огромных личностных усилий; требования сегодняшнего дня заставляют обретать мастерство в достаточно сжатые сроки, ограниченные, с одной стороны, возрастными рамками, с другой - конкурсными (один из наиболее популярных способов осуществить исполнительскую карьеру - участие в международных конкурсах). И именно этот путь чреват огромными опасностями, среди которых можно назвать не только стремление к «идеальному» пианизму, что может привести к определенной «выхолощенности» и «безликости» исполнителя (об этом говорят многие музыканты), но и опасность временного «неуспевания» для глубинного смыслового проникновения в сложные музыкальные произведения (в силу возраста, коротких временных сроков изучения или, наоборот, постоянного повтора так называемой «конкурсной» программы на огромном количестве конкурсов). Но, возможно, нежелание «утомлять себя» психологическими конфликтными противоречиями, которых требует исполнение, вызвано и определенной слушательской аудиторией, которая не готова к серьезной интеллектуальной и эмоциональной работе. Однако глубинное проникновение в смысл исполняемого произведения остается фундаментальным условием исполнительского мастерства, обязательно требует дальнейшего изучения конфликта как психологического исполнительского феномена.

\section{СПИСОК ЛИТЕРАТУРЫ}

1. Аркадьев М. Эскиз философии дирижерского ремесла. URL: http://arkadev.com/array/node/9\#!prettyPhoto[iframes]/1/ (дата обращения: 02.03.2020).

2. Браудо И. Об органной и клавирной музыке. Москва : Музыка, 1976. $149 \mathrm{c}$. 
3. Гришина Н. Психология конфликта. Санкт-Петербург : Питер, 2008. 544 с.

4. Лосев А. Музыка как предмет логики. Из ранних произведений / А. Лосев. Москва : Правда, 1990. С. 195-369.

5. Мазель Л. Работы последних десятилетий о ритме. Музыкальная академия. Москва, 1995. № 2. URL: http://www.arkadev.com/ (дата обращения: 10.03.2020).

6. Самойленко О. Психологія мистецтва: сучасні музикознавчі проєкції : монографія. Одеса : Видавничий дім «Гельветика», 2020. $236 \mathrm{c}$.

7. Haga E. Correspondences between music and body movement : Ph. D. thesis. Derpartment of Musicology University of Oslo. Oslo, 2008. $263 \mathrm{p}$.

\section{REFERENCES}

1. Arkadyev, M. (2020). The sketch of the conducting craft philosophy. Retrieved from http://arkadev.com/array/node/9\#!prettyPhoto[iframes]/1/ [in Russian].

2. Braudo, I. (1976). About the organ and clavier music. M.: Music [in Russian].

3. Grishina, N.V. (2008). The psychology of conflict. SPb: Piter [in Russian].

4. Losev, A.F. (1990). Music as the subject of logic. From the early works. M.: Pravda, P. 195-369 [in Russian].

5. Mazel, L.A. (1995). The works of the last decades on rhythm. Music academy. M., № 2. Retrieved from http://www.arkadev.com/ [in Russian].

6. Samoilenko, O.I. (2020). Psychology of art: the modern musicological projections: monograph. Odesa: Helvetica publishing house [in Ukrainian].

7. Haga, E. (2008). Correspondences between music and body movement. Ph. D. thesis. Department of Musicology University of Oslo [in English]. 